\title{
LUKÁCS: TRABALHO, OBJETIVAÇÃO, ALIENAÇÃO
}

Sergio LESSA ${ }^{1}$

- RESUMO: O artigo busca esclarecer a distinção fundamental entre a positividade ontológica da objetivação e da alienação segundo György Lukács e a negatividade intrínseca a estes conceitos entre uma enorme gama de pensadores. Para tanto, o artigo toma por eixo as diferenças entre o filósofo húngaro e Hegel, que postulou de forma clássica a negatividade dos momentos da alienação e da objetivação.

- UNITERMOS: Trabalho; alienação; objetivação; Lukács; Hegel.

O complexo problemático composto pelas categorias do trabalho, alienação, objetivação e estranhamento foi tratado por Lukács de uma forma distinta daquela utilizada pela enorme maioria dos pensadores contemporâneos. Neste artigo, longe de esgotarmos a riqueza e a complexidade do tratamento de Lukács a estas questões, procuraremos delimitar um traço que nos parece central e peculiar do modo como Lukács tratou desta problemática: a positividade inerente ao complexo objetivação/alienação. Isto nos obrigará a incursões nas categorias do trabalho e do estranhamento. Todavia, e muito mais em relação à segunda que à primeira, estas incursões serão meramente indicativas de alguns elementos imprescindíveis ao desvelamento do caráter de positividade da objetivação e da alienação em Lukács.

Segundo Lukács, a categoria do trabalho é a categoria fundante do ser social. ${ }^{2}$ No contexto da ontologia lukácsiana, ${ }^{3}$ isto significa que, por um lado, a gênese da categoria do trabalho corresponde à gênese de uma nova esfera do ser, de uma nova

1. Professor da Universidade Federal de Alagoas. Doutorando no Departamento de Ciências Sociais da UNICAMP.

2. Luckács, G. Per una ontologia dell'essere sociale, Roma: Riuniti, 1976-81, v. 1, p. 256 ss., v. 2, p. 81.

3. O emprego da expressão "ontologia lukácsiana" não conta com a unanimidade das opiniões entre os estudiosos de Lukács. José Paulo Netto, por exemplo, afirma que há uma ontologia marxista do ser social, e que o esforço do filósofo resultou em desenvolvê-la e explicitá-la. Não temos certeza de podermos concordar com estas opiniões; todavia não é nosso objetivo discuti-las aqui, já que envolveria uma disputa acerca da obra de Marx que não cabe no escopo pretendido a este trabalho. Deste modo, a expressão ontologia lukácsiana designará, neste projeto, especificamente o fato de que estaremos nos referindo à pesquisa de Lukács enquanto tal, deixando para um outro momento o confronto entre ela e os escritos de Marx. 
substancialidade, radicalmente distinta do ser apenas natural. ${ }^{4} \mathrm{E}$, por outro lado, que o trabalho fornece a protoforma, o modelo genérico, da práxis humano-social.

Detenhamo-nos sobre cada um desses aspectos.

\section{Gênese do trabalho e gênese do ser social}

Segundo Lukács, o ser é fundamentalmente histórico. A esfera inorgânica se constituiu em base para o desenvolvimento posterior da vida, e esta se desdobrou como patamar ineliminável do ser social. Entre as três esferas do ser - a inorgânica, a biológica e a social - há, segundo Lukács, uma continuidade que se estende do desenvolvimento das primeiras formas materiais, simples e pouco articuladas, às mais ricas e capazes de desenvolver uma dinâmica reprodutiva muito complexa.

Argumenta o filósofo húngaro, todavia, que esta linha de continuidade não deve velar o fato de que entre as distintas esferas ontológicas se interpõem traços de descontinuidade bastante acentuados. Tais descontinuidades são fundamentais no surgimento e posterior desenvolvimento da legalidade específica a cada uma das esferas.

Em outras palavras, o salto qualitativo representado pela passagem do inorgânico à vida tem um duplo efeito. Por um lado, assinala a gênese de uma nova esfera de ser, qualitativamente distinta da anterior. Por outro lado, instaura na natureza uma processualidade cuja continuidade é dada por um processo reprodutivo que apenas pode se efetivar tendo por base a natureza inorgânica. Neste sentido, se há uma irredutibilidade ontológica das leis da vida às da esfera inorgânica, não menos verdadeiro é que a esfera pode surgir e se reproduzir tendo por base o mundo inorgânico.

Mutatis mutandis, algo análogo pode ser apontado em relação ao ser social. É indispensável uma base biológico-natural para permitir o aparecimento da categoria trabalho. Todavia, a legalidade social é ontologicamente distinta da natureza. ${ }^{5}$

4. "O devir do homem é, como processo global, a mesma coisa do constituir-se do ser social enquanto espécie particular de ser." Lukács, op. cit., v. 2, p. 570.

5. Neste sentido, Lukács faz duras críticas a Engels que, no Capítulo XIII da Parte I do Anti-Dühring, afirma que tanto a transformação de uma montanha em vale, como de uma semente em planta, ou de uma monarquia numa república, exibem a mesma processualidade dialética da negação. Para o filósofo húngaro, este procedimento de Engels nada mais faz que colocar sob uma mesma categoria abstratamente genérica - a negação processualidades ontologicamente distintas, velando as estruturas de ser nelas operantes. Brevemente, argumenta Lukács que a negação é uma categoria apenas presente no ser social, pois só nesta esfera temos processualidades que destróem, no sentido ontológico do termo, algo preexistente, criando algo ontologicamente novo. Deste modo, enquanto o desenvolvimento da semente para a planta se mantém no interior de uma mesmalegalidade ontológica, algo radicalmente oposto ocorre com a destruição de uma árvore para a fabricação de papel. Em primeiro lugar, este apenas pode vir a ser através de um ato teleologicamente posto, portanto, um ato humano-social; e, em segundo lugar, a legalidade operante na história concreta deste papel, fabricado em dadas situações histórico-sociais, nada tem de natural. Isto se evidencia, por exemplo, se o papel for uma mercadoria. Cf. Lukács, op. cit., v.1, p.196 ss. 
Assinala Lukács que a compreensão adequada da complexa problemática do salto ontológico que marca a passagem da esfera inorgânica à vida, e desta ao ser social, requer a consideração da atuação do momento predominante (uebergreifendes Moment) nesse tipo de processualidade. Lembra ele que o momento predominante é uma inovação de Marx em relação à dialética hegeliana. ${ }^{6}$ Enquanto em Hegel as determinações reflexivas se moviam, eram impulsionadas, pela pura contraditoriedade, para Lukács - após Marx -, a mera contraditoriedade não poderia senão conduzir a um equilíbrio estático entre os pólos contraditórios. " ".../ se queremos dar uma expressão conceitual à dinâmica viva do ser, ao seu desenvolvimento, devemos elucidar qual seria, na interação da qual se trata, o momento predominante. É esta, com efeito, - não simplesmente a sua ação, mas também as resistências contra a qual se choca, que ele próprio desencadeia etc. - que dá uma direção, uma linha de desenvolvimento, à interação que, não obstante todo seu movimento parcial, seria de outro modo estática." 8

No salto da esfera inorgânica para a esfera biológica, o momento predominante é exercido pelas novas categorias pertencentes à esfera da vida. A categoria da reprodução, por exemplo, já está presente nas primeiras formas de vida, pois, caso contrário, estas formas sequer poderiam ser biológicas. Analogamente, no salto da vida meramente biológica à vida social, a direção do movimento é dada pelas categorias do novo ser. E este vir-a-ser é, ao mesmo tempo, resultado do processo evolutivo e conteúdo concreto do salto qualitativo.

Alerta Lukács que, certamente, este quadro genérico não resolve todos os problemas relativos às formas concretas, às mediações reais, aos momentos de ruptura etc., desta complexa processualidade que consubstancia a passagem da natureza ao ser social. Estes apenas podem ser determinados pela pesquisa científica, e não por um estudo de caráter ontológico, geral. Todavia, já este nível de generalidade ontológica permite a "verificação/.../ [deste] fato: a reprodução biológica da vida forma a base de todas as manifestações vitais do ser social, a primeira sem a segunda é possível, o contrário, não". ${ }^{9}$ A humanidade, para continuar a existir e a se reproduzir

6. Sobre o momento predominante em Marx, cf. Introduction génerale a la critique de l'economie politique, C. de la Pléiade, aos cuidados de M. Rubel, Paris: Gallimard, 1965, v. Economie I, p. 247.

7. Lukács, G. Os princípios ontológicas fundamentais de Marx, São Paulo: Ciências Humanas, 1979, p. 70 ss.

8. Lukács, G. Per una ontologia dell'essere sociale, v. 2, Roma: Riuniti, 1981. p.229.

9. Idem, p. 234. Estas palavras de Lukács são uma indicação precisa do quão frontalmente ele se opõe ao Gesellschaftszentrismus, ao "sociocentrismo", da Escola de Frankfurt, como à deducibilidade da legalidade social a partir da natureza, como faz o marxismo vulgar. Entre a dissolução de todo o ser no mundo dos homens e a redução do ser social à natureza, o filósofo húngaro buscou um tertium datur: o ser social é ontologicamente distinto e ontologicamente conexo à natureza. O elo desta articulação - processual, histórica - é o trabalho. Nesse sentido, tem razão Nicolas Tertuliam quando argumenta ter a ontologia de Lukács um caráter de philosophia universalis, um caráter de ontologia geral - ainda que seu objetivo privilegiado seja o mundo dos homens. Sobre estas colocações de Tertuliam, cf. "Teologia e causalità in Luckács", in Critica marxista, Roma: Riuniti, n.5, 1989 - ainda que não concordemos com suas considerações acerca da categoria da essência em Lukács, nos últimos parágrafos do artigo. 
enquanto tal, deve ser capaz de levar a cabo com sucesso as exigências postas pela sua própria reprodução biológica.

Todavia, esta ineliminável ligação entre a natureza e a categoria do trabalho, entre a reprodução biológica e a reprodução social, apenas esclarece um aspecto do problema aqui envolvido. A ineliminável conexão do ser social com sua base biológica nos permite entrever a prioridade ontológica da reprodução material da vida na processualidade social. Mas não permite o desvelamento das categorias específicas do mundo dos homens.

O que distingue o ser social da natureza não é o fato de ter como exigência primeira a reprodução da sua própria forma de vida. Muito pelo contrário, isto é o que aproxima a reprodução social da reprodução natural, num plano de elevada abstração. ${ }^{10} \mathrm{O}$ que as distingue radicalmente é a forma ${ }^{11}$ do desdobramento concreto do processo reprodutivo nas duas esferas. A determinação do ser-precisamente-assim da reprodução biológica é dada por seu momento predominante, isto é, pelas categorias biológicas; a mesma determinação, no mundo dos homens, é dada pela categoria do trabalho.

O que possibilita à categoria do trabalho ser fundamento da especificidade ontológica da reprodução social?

É a sua peculiar constituição interna. Como o exame desta sua constituição será feita no próximo item, aqui apenas indicaremos o seu traço mais importante e a sua conseqüência mais geral para a reprodução social, sempre segundo Lukács: o trabalho detona uma processualidade que, por si própria, remete sempreà universalidade. Este remeter à universalidade engloba dois momentos contraditória e intrinsecamente articulados. Por um lado, remete à universalidade os produtos do próprio trabalho; por outro, faz o mesmo com o sujeito que realiza o trabalho. Assim, tanto o produto do trabalho - no limite, a própria formação social -, como os indivíduos que o efetivam, adquirem um conteúdo concreto, material, cada vez mais universalizado, genérico.

Disso decorre, fundamentalmente, que o conteúdo concreto, ou seja, a substância social, tanto dos indivíduos como das formações sociais no seu todo, são cada vez mais sociais na sua essência. Com isto não queremos sugerir que a essência humana possa não ser social para Lukács. Fazê-lo, significaria se contrapor ao cerne da sua ontologia. Desejamos apenas apontar o fato de que a essência humana corresponde a uma processualidade, ao decurso histórico concreto que conduz à elevação da humanidade a níveis superiores de sociabilidade. Nesse sentido, em nível da máxima generalidade e sem desconsiderar os momentos de contraditoriedade, o desdobramento categorial do ser social corresponde ao processo histórico que Lukács denominou Menschwerden des Menschen, o devenir homem dos homens. ${ }^{12}$

\footnotetext{
10. Per una ontologia..., v. 2.

11. Valeria a pena lembrar que, na tradição marxiana, a forma nada mais é que a maneira de expressão de um conteúdo. Portanto, entre eles se desdobra uma contraditoriedade, uma tensão permanente de determinações reflexivas.

12. Cf. Nota 3. Idem, p. 570. Sobre a historicidade da categoria da substância em Lukács. Cf. Idem, p. 260-1.
} 
O devenir homem dos homens é uma categoria rica em conteúdos e determinações, no contexto da ontologia lukácsiana. O que é imprescindível, neste momento, é assinalar, em primeiro lugar, que esta categoria é, em Lukács, puramente ontológica, ela corresponde ao ser-precisamente-assim do ser social, e não a um hipotético deve-ser social.

Em segundo lugar, salientar que, justamente por ser uma processualidade ontológica, sua evolução se consubstancia em transformações materiais, concretas, do ser humano. ${ }^{13}$ Desta maneira, o conteúdo concreto do ser-homem ao longo do tempo se transforma ao se desdobrar em uma substancialidade mediada por categorias sociais cada vez mais complexas e articuladas. Os indivíduos humanos se desenvolvem em autênticas personalidades, em individualidades cada vez mais sociais, crescentemente mediadas por categorias puramente sociais, cada vez mais genéricas. As formações sociais, analogamente, adquirem formas materiais e espirituais genéricas cada vez mais desenvolvidas. Esta generalidade, portanto, não é uma mera abstração, mas uma universalização realizada pelo próprio real: é a própria histónia. ${ }^{14}$ A esta universalidade concreta Lukács denominou generidade (Gattungsmaessigkeit).

Neste sentido, a categoria do trabalho é, em Lukács, tanto a forma originária (Vorbild) da práxis humano-social como o fundamento (Urform) ontológico do mundo dos homens. Ou seja, por ser a forma originária do ser social, seu fundamento ontológico último, os traços ontológicos mais gerais do trabalho, acima de tudo a peculiar dialética entre teleologia e causalidade estão presentes, ainda que por vezes sob formas bastantes modificadas, em todos os atos humanos. Portanto, o fato de Lukács utilizar os termos Urform e Vorbild como quase sinônimos, ao se caracterizar o papel ontológico do trabalho na processualidade social, está longe de expressar uma imprecisão terminológica do filósofo húngaro. Antes, exprime com rigor a proximidade ontológica entre o fato de o trabalho ser a forma originária (Urform) e, justamente por isso, conter traços ontológicos mais gerais dos atos humanos (Vorbild). ${ }^{15}$

Portanto, a gênese do trabalho é o processo fundante da complexa explicitação da essência humana, do devenir humano dos homens. É o início da autoconstituição da humanidade enquanto gênero, é o momento fundante da generidade em-si. Nesse exato sentido, a gênese da categoria do trabalho é a gênese do ser social.

Todavia, isto é apenas um aspecto da questão. De fato, com este rústico esboço da generidade, chegamos até onde senia possível chegar, nesta constelação problemática, sem adentrarmos à análise da estrutura ontológica do trabalho enquanto tal. Passaremos, por isso, ao estudo do em-si da categonia do trabalho e, com os resultados desta investigação, poderemos nos debruçar sobre o outro aspecto desta problemática.

13. Idem, p. 574 .

14. Idem, p. 183

15. Sobre a discussão do uso de Vorbild e Urform por Lukács, ainda que não possamos concordar com todas as colocações do artigo, cf. Franco, Vittoria. "Il lavoro come 'forma originária' nell'ontologia de Lukács" in Critica marxista, Roma: Riuniti, 1977. n.3. 


\section{Trabalho e práxis social}

\section{Ideação e objetivação}

Retomemos a questão: o que possibilita ao trabalho ser a categoria fundante do ser social? Indicamos, anteriormente, ser sua constituição interna específica, sua essência. Devemos agora desvelar qual é a essência do trabalho para Lukács.

O nódulo essencial do trabalho é, segundo Lukács, uma peculiar e exclusiva articulação entre teleologia e causalidade.

Todo ato de trabalho, segundo o filósofo húngaro, tem no momento ideal, na prévia-ideação, seu ponto de partida. ${ }^{16}$ Ë impensável qualquer ato humano que não se apresente desta forma.

Indubitavelmente, este momento ideal, na sua imediaticidade, é singular e abstrato. A simples hipótese do desaparecimento físico do indivíduo cuja consciência é portadora desta ideação nos auxilia a compreender este fato. Enquanto singularidade e abstratividade absolutas, todavia, este momento ideal não deixa de exercer uma ação concreta, material, no comportamento também concreto e materialmente verificável do seu portador. Neste sentido, a ação deste momento de prévia-ideação é mais "real", no desdobramento da vida do indivíduo, que uma montanha de minério de ferro. Ele determina o comportamento social do indivíduo com uma intensidade muito maior do que qualquer objeto natural o faz.

Todavia, para dar existência objetiva ao previamente-idealizado, o indivíduo deve, por força das coisas, transformar em algum grau o mundo que o cerca. ${ }^{17}$ Esta transformação pode ser de ordem primária, ou seja, voltada diretamente à transformação da natureza; ou de ordem secundária, isto é, que visa a transformar, a influir sobre os momentos de prévia-ideação de outros indivíduos, levando-os a adotarem determinados comportamentos que se julgam desejáveis. ${ }^{18}$ Devemos salientar que o momento de prévia-ideação apenas existe enquanto prévia-ideação de uma ação voltada à transformação do mundo em que se vive. Ele tem sempre um caráter de resposta às necessidades concretamente postas pela vida.

Este momento de transformação do real com base em uma ideação, em si singular e abstrata, é denominado por Lukács objetivação. ${ }^{19} \mathrm{O}$ nódulo fundamental da objetivação, sempre segundo Lukács, é o fato de que, nela, o previamente-idealizado ganha uma existência objetiva, concreta, própria - que, em escala variável caso a caso, independe dos desejos e das prévias-ideações do seu criador. O ideal ganha

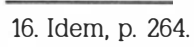

17. "/.../ todo movimento no curso (ou antes) do trabalho são dirigidos em primeiro lugar à objetivação." Idem, p. 564.

18. Idem, p.155.

19. " /.../ enquanto Marx descreveu (o trabalho) com uma terminologia unitária, ainda que variada, eu analiticamente o cindi em objetivação e alienação. /.../ No ato real, em verdade, os dois são inseparáveis." Idem, p. 564. 
existência material, o, abstrato traspassa em concreto, o momento ideal em objetividade.

A objetivação inevitavelmente possui um momento de alienação. Seja o produto criado um machado ou uma idéia, uma vez objetivados, inseridos na malha de determinações da situação social concreta, ganham uma dinâmica própria. A história do produto objetivado, em definitivo, deixa de ser idêntica à história do seu criador. Neste sentido, a objetivação, enquanto momento ontológico ineliminável de todo ato de trabalho, cria novos seres e novas relações entre os homens, seres e relações, estes sobre cuja história os seus criadores possuem apenas controle parcial. A esta distinção ontológica entre o criador e o seu produto, Lukács denomina alienação.

Devemos salientar, que, para Lukács, o momento da alienação é essencialmente positivo: é a afirmação prática da generidade. Ser humano, tanto no plano da sociabilidade como um todo, como no plano da individualidade, é desenvolver uma capacidade cada vez maior de se alienar, isto é, de objetivar prévias-ideações.

A positividade intrínseca à alienação é um traço distintivo da ontologia lukácsiana diante de uma enorme gama de pensadores. Desde Haron Arré, representante da psicologia social inglesa, até "hegelo-marxistas" como Carol Gould, passando por Lucien Goldmann, Marcuse e a enorme maioria dos biógrafos e vulgarizadores de Marx, - todos em que pese a enorme diferença entre eles tomam a alienação enquanto negação do humano. Neste sentido, novamente apesar das significativas distinções de qualidade e opinião entre estes pensadores, todos eles se aproximam, de uma forma ou de outra, da formulação clássica da alienação enquanto intrinsecamente negativa, aquela de Hegel na Fenomenologia do Espínto. Assim, para ganhar em concisão sem perder em densidade, em vez de uma polêmica com cada um desses pensadores ou correntes, optamos por salientar a distinção existente entre Hegel e Lukács, neste particular

\section{Hegel, objetivação e alienação}

Segundo Hegel, ${ }^{20}$ o espírito imediato ou natural, correspondente à unidade entre indivíduo e sociedade característica do mundo antigo, se dissolveu no mundo das pessoas privadas, do mercado. Nesse mundo, a substância espiritual primeira se transmutou em relação formal de indivíduos singulares, que tão-somente se reconhecem como pura certeza (abstrata) de si. No entanto, este mesmo movimento, em seguida, impulsiona o espírito a uma nova etapa, à redescoberta de si próprio, à sua

20. Os conceitos de objetivação e alienação passam por modificações, apresentam diferentes nuanças ao longo de suas obras. O periodo juvenil, neste particular, apresenta diferenças significativas se comparado com as obras posteriores à Ciência da lógica (cf. Lukács, G. Eljoven Hegel, México: Grijalbo, 1963, em especial o último capítulo). Como, no entanto, a formulação hegeliana que mais tem influenciado é aquela da Fenomenologia do Espírito, optamos por focar nossa atenção sobre a VI parte, "O Espírito", desta obra, onde encontramos uma formulação hegelianamente clássica dos conceitos que agora nos interessam. 
nova unidade: à autoconsciência do espírito. Seguir os nódulos centrais deste percurso, delineado na Fenomenologia do Espínto, nos permitirá ter acesso ao cerne do conceito hegeliano de alienação.

O primeiro momento na trajetória do espírito é a unicidade entre o indivíduo, a pólis, os costumes, a tradição etc. O mundo e a consciência eram unívocos. O primeiro era vivido de forma espontânea, sem que fosse considerado distinto dos indivíduos. Todavia, esta situação se traspassa ${ }^{21}$ em outra, onde "os costumes, a vida familiar e social, o poder da cidade, passou a ser agora para o em-si insular e exclusivo algo distinto dele mesmo, um outro que, sem embargo, não se pode dizer que seja absolutamente outro". ${ }^{22}$ Hegel: " ".../ o mundo tem então a determinação de ser uma exterioridade, o negativo da autoconsciência"; "uma obra /.../ na qual esta não se reconhece a si mesma..."23

Este mundo alienado, surgido da desagregação do mundo antigo e que Hegel situa no período que vai da Idade Média até o século XVIII, é definido como o período da cultura (ou da civilização-Bildung). "Este mundo já não é, como o primeiro mundo do espírito, um todo harmonioso que repousa em si mesmo, mas um mundo dividido e rompido, o mundo do espírito que se fez estranho a si mesmo (entfremdete)." "24

Nele, a unidade essencial, a do espírito, só pode ser postulada num plano que transcenda a bipartição do mundo imediato: é a fé. Isto significa que a consciência do espírito sobre si mesmo é agora dupla: há um mundo efetivo, objetivo, no qual a unidade do em-si com a essência é apenas postulada, mas nunca efetivada. E um mundo para além daqui, onde esta unidade é sempre realizada. Hegel expressa esta nova situação afirmando que: "A presença tem sua oposição imediatamente em seu para além, que é seu pensamento e seu ser-pensado; inversamente, este tem sua oposição no mais próximo, que é sua efetividade que se fez estranha." 25

Característico da Bildung é o fato de o indivíduo renunciar ao seu direito natural em favor de um estado civil e, ao fazê-lo, conectar-se ao universal. O indivíduo, "através da mediação que é o estranhamento, se colocou em consonância com o universal". ${ }^{26}$

Vejamos como isto se dá: lembremos do momento da fundação da vontade geral de Rousseau ${ }^{27}$ Nele, a alienação dos direitos individuais surge como requisito para a formação do corpo político. Segundo Hegel, isto não passa de uma metáfora pela qual

21. O que leva a este movimento é, em última análise, a dialética entre o ser e o nada, onde o não-ser, a negação ontológica, é logicamente atenuada até se converter no não-ser do ser-outro. Sobre a crítica de Lukács a este procedimento hegeliano, cf. Per una ontologia, v.1, p. 195-9.

22. Hyppolite, J. Génesis y estructura de la fenomenologia del espiritu de Hegel. Barcelona: Ed. 62, 1974, p. 344.

23. Hegel, G.W.F. La phénoménologie de l'esprit. Tradução de J. Hyppolite, Local: Aubier, 1941, v. 2, p. 50.

24. Hyppolite, op. cit., p. 343.

25. Idem, p. 51.

26. Idem, p. 55.

27. Rousseau, J.-J. Do contrato social ou principios do direito político. São Paulo: Abril, 1978, p. 31-3, (Os Pensadores). Sobre a alienação do indivíduo à vontade geral, cf. o excelente ensaio de Salinas Fortes, L.R. Rousseau: da teoria à prática. São Paulo: Ática, 1976. 
o espírito explica a si próprio, o movimento indispensável (pois correspondente à sua essência) de autonegação do indivíduo insular que, por meio da vontade geral, se eleva ao universal. Neste mundo estranho da Bildung, a essência do espírito - sua universalidade - aparece como resultante de um movimento do indivíduo insular, que assume a aparência de essência universal. Essencialidade e esfera fenomênica estão, aqui, invertidos, segundo a ótica hegeliana: o todo torna-se posterior às partes, a universalidade é fundada pela singularidade. Todavia, este momento estranhado é fundamental, pois por meio dele o indivíduo insular se eleva à essencialidade do universal e constitui - de forma alienada - o corpo político. Esta passagem singular ao universal é decisiva; todavia, tem seu preço: indivíduo e universalidade se opõem como estranhos. O indivíduo já não encontra a si mesmo. O espírito está desgarrado, sua forma de universalização é a ele estranha.

A tensão decorrente deste estranhamento, onde o espírito universal se reconhece enquanto produto da alienação do indivíduo ao universal - ou seja, onde este espírito universal postula a si próprio enquanto produto da vontade individual que se auto-aliena na vontade geral -, " produzirá o estranhamento do estranhamento e, deste modo, a totalidade voltará a tomar a si própria em seu próprio conceito" . ${ }^{28}$

Este movimento de superação do mundo estranhado se inicia pela Ilustração, pelo combate às trevas, tendo por motor a insuportável contradição entre o Estado absolutista - "que sou eu" - e o desejo de riqueza por parte dos indivíduos. ${ }^{29}$

Enquanto a fé é a fuga do mundo da cultura (Bildung), a razão (Einsicht) é o seu resultado. O movimento de fuga e o movimento de conquista do real se entrechocam, Iluminismo e fé se contrapõem, a escuridão começa a ser superada. Todavia, apenas com a Revolução Francesa, quando o espírito se efetivará a si próprio pelo reconhecimento de seu em-si, quando o espírito se tornar absoluto, estará superado o campo da alienação.

Este breve esboço será suficiente, esperamos, para permitir um confronto esclarecedor entre Lukács e Hegel.

Hegel insiste em que a alienação, inexistente num primeiro momento (aquele do espírito natural), nada mais é que a negação da essência do espírito. Neste contexto, alienação (Entaeusserung) e estranhamento (Entfremdung) surgem como quase sinônimos, o que é perfeitamente compreensível da perspectiva hegeliana.

Se a objetivação nada mais é que a perda do espírito de si próprio, já que toda objetivação é necessariamente alienante no sentido do estranhamento, então não há como objetivação, alienação e estranhamento deixarem de ser apenas aspectos lógicos distintos de uma mesma processualidade, de um mesmo momento do ser, qual seja, o movimento de desgarramento do espírito de si próprio. Neste círculo de

28. Hegel, G.W.F. La phénoménologie..., op. cit., p. 58.

29. Sendo extremamente breve: esta passagem se dá através do fato lingüístico que todo nome designa a universalidade: através da linguagem, o eu do monarca que corporifica o Estado ganhou expressão universal. Chegamos ao Estado absolutista, ao "Estado sou eu". 
ferro de negatividades, toda alienação implica o estranhamento da essência, e a sua positividade se limita à construção da Bildung enquanto negação da essência.

Em Lukács, pelo contrário, objetivação/alienação são momentos essencialmente positivos, são acima de tudo a afirmação prática, efetiva, do ser humano enquanto ser genérico. ${ }^{30}$ Em Hegel, a objetivação/alienação/estranhamento não passa de uma etapa da evolução do espírito, etapa em que o espírito nega sua própria essência, em que o espírito não reconhece a si próprio; para Lukács a objetivação/alienação é precisamente o momento em que o ser humano objetiva uma prévia-ideação e, nesse exato sentido, é o momento de afirmação do ser humano enquanto ser genérico — daqui a universalidade destas categorias.

A objetivação/alienação em Lukács, portanto, é um momento ineliminável, um componente ontológico imprescindível, da práxis humano-social, do devenir humano dos homens. Apenas se alienando podem os homens, enquanto indivíduos e enquanto humanidade, se constituírem como tais. Em definitivo, para Lukács, não há ser social sem objetivação/alienação. ${ }^{31}$

Ainda mais: a positividade de Lukács reconhece na alienação nada mais que uma outra maneira de afirmar o ser social enquanto resultado das atividades humanas, enquanto histórico e puramente social. Nesse sentido, a afirmação da positividade da alienação é um aspecto fundamental da ruptura ontológica com Hegel. Tomar como essência da história o espírito absoluto conduziu à concepção teleológica do ser e à alienação enquanto essencialmente negativa. Não menos importante, também, é o fáto de a superação da alienação postulada por Hegel ter um nítido caráter teleológico, estando associada a um conjunto de pressupostos que Lukács denominou de "Falsa Ontologia". ${ }^{32}$ Em Lukács, muito pelo contrário, nenhuma teleologia enquanto categoria universal pode ser encontrada, apenas na práxis a teleologia é um momento fundamental. ${ }^{33}$

Em definitivo: no contexto da ontologia lukácsiana, reconhecer, na práxis humano-social, o fundamento ontológico do devenir humano dos homens implica

30. Nossa interpretação difere frontalmente da de Andre Tosel. Tosel argumenta que a alienação, em Lukács, "designa o efeito de retorno exercido sobre os indivíduos por esta objetivação /.../ designa o surgimento, a formação de novas necessidades, finalidades pela retroação da práxis objetivante enquanto tal, e isto de maneira contraditória e sempre ideologicamente determinadas. Lukács retoma aqui um determinado Hegel, aquele do espírito objetivo em sua positividade". Consideramos que, mais que um "efeito de retorno" sobre o sujeito agente, a alienação é um traço ontológico ineliminável da objetividade do mundo dos homens. Em sendo assim, Lukács se distingue radicalmente de Hegel. Cf. Tosel, A. "Le courage de l'intempestif: 1", Ontologie de l'être social, de G. Lukács, in La Pensée, 248, 1985.

31. Esta concepção de Lukács é diametralmente oposta a colocações como as de Carol Gould ou Joachim Israel, que restringem, cada um a sua maneira, o fenômeno da alienação à sociedade capitalista. Cf. Gould, C. Ontologia social de Marx, México: Fondo de Cultura Económica, 1983; e Israel, J. Teoría de la alienación. Barcelona: Peninsula, 1977.

32. Lukács,G. Per una ontologia..., op. cit., v.1, p.165-214.

33. Cf., por exemplo, a análise de Lukács sobre o tempo de trabalho socialmente necessário enquanto categoria do mundo econômico. Idem, p. 216/CIII ss. 
tanto a concepção histónica e não teleológica do ser como na positividade do momento da alienação.

\section{Objetividade e ideação}

Isto posto, faremos algumas breves observações acerca da relação entre o ente objetivado e a subjetividade, naquele percurso que Lukács denomina "ação de retorno" do objeto sobre a subjetividade. A rigor, com isto estamos saindo do tema proposto a este artigo; todavia, julgamos imprescindível estas breves indicações para melhor delinear o conjunto de questões nele envolvido.

A prévia-ideação é o momento predominante no movimento da objetivação. De fato, é ela que determina o porquê e o como da efetivação deste ou daquele ato. Tal é o fundamento ontológico último para que a consciência não se resuma a um mero epifenômeno na processualidade social. Ela, ao contrário, é um momento fundamental na determinação da forma e do conteúdo da práxis humana e, nesse sentido, é uma mediação essencial na conformação ontológica da substância social.

Subjetividade e materialidade são, portanto, dois momentos distintos, porém ontologicamente articulados, do mesmo ser. A materialidade humana não pode vir a ser sem o momento teleológico, todavia este apenas se põe enquanto resposta às situações concretas que a vida coloca aos indivíduos e às formações sociais como um todo. Se a materialidade do mundo dos homens é a subjetividade objetivada, não menos verdadeiro é que a consciência humana apenas existe enquanto órgão e médium da continuidade do peculiar processo de acumulação que é a reprodução social. Neste sentido, repetimos, a consciência, para Lukács, está longe de ser um mero epifenômeno da existência social; pelo contrário, tem ela um peso ontológico fundamental na determinação do mundo dos homens. ${ }^{34}$

Contudo, ao se tratar da "ação de retorno" do real objetivado sobre a consciência, o momento predominante se desloca da subjetividade para a realidade em-si.

Neste movimento de retorno, a nova esfera de relações posta pela objetivação, a materialidade - em oposição à subjetividade, ao momento ideal - passa a exercer o momento predominante. É ela que coloca as demandas às quais os indivíduos - e as sociedades como um todo - devem responder com ações concretas se não desejam desaparecer. É ela, também, que circunscreve os limites objetivos de possibilidade às alternativas abertas à ação humana em cada momento histórico. ${ }^{35}$

34. São muito elucidativas das posições de Lukács a este respeito não apenas sua discussão sobre a problemática da ideologia, mas também o tratamento que confere à problemática dos valores em Per una ontologia... Todavia, não se trata, agora, de explorar este aspecto do problema.

35. Nas palavras de Lukács: "A unidade objetiva incindivel entre objetivação e alienação permanece, ainda que na sua estrutura interna se verifiquem importantes alterações. Aquela de maior importância é uma certa preponderância objetiva que assume a alienação, uma vez objetivada a posição teleológica." Idem, v. 2, p. 600. 
Esta ação de retorno sobre a subjetividade, na enorme maioria dos casos, se constitui em momento fundamental do impulso a formas superiores de generidade. Ao confrontar objeto criado/indivíduo criador como dois entes cujas histórias não são mais idênticas, a alienação permite o confronto entre a subjetividade, que operou a prévia-ideação, e o ser-precisamente-assim existente. Este confronto, dinâmico e cujo horizonte é a práxis social como um todo, é o fundamento ontológico do desenvolvimento da subjetividade humana. ${ }^{36}$

Todavia, em dadas circunstâncias históricas - e sem universalidade e a necessidade presentes na alienação/objetivação - emerge a categoria do estranhamento. Em síntese, esta categoria é composta pelos momentos reais nos quais o objetivado, na sua ação de retorno sobre a subjetividade, exerce um papel negativo, no sentido de conter, impedir momentaneamente, o desenvolvimento do gênero humano. Não pretendemos agora discutir sequer minimamente esta categoria lukácsiana; mas apenas chamar a atenção para duas relações:

1. o estranhamento, para Lukács, se consubstancia no momento de negatividade em relação à positividade intrínseca à alienação/objetivação. Ser estranhado significa não-ser-humano, não-humanidade está posta pela própria práxis humanosocial;

2. a categoria lukácsiana do estranhamento apenas pode ser concebida numa constelação teórica nạ qual o movimento de objetivação/alienação seja reconhecido na sua positividade e, na qual, o objetivado exerça o momento predominante na determinação entre o real e a subjetividade.

\section{Conclusão}

Portanto, e concluindo, o caráter de positividade do binômio objetivação/alienação joga, no interior da ontologia lukácsiana, um papel fundamental. Em primeiro lugar está relacionado diretamente à postulação lukácsiana da radical historicidade e sociabilidade do mundo dos homens. Se o mundo dos homens é o complexo resultado do agir humano, se a práxis é o fundamento do ser social, então a processualidade objetivação/alienação corresponde à consubstanciação do devenir humano dos homens: daqui sua positividade. Sem mais, tal traço é um elemento ineliminável, central, na ruptura operada por Lukács com toda ontologia tradicional (incluída a hegeliana).

Em segundo lugar, a positividade do processo de objetivação-alienação está intrinsecamente articulada à gênese e ao desenvolvimento, a partir de um dado patamar de desenvolvimento histórico, de uma instância de negatividade; isto é, da gênese de obstáculos histórico-sociais à plena explicitação do gênero humano. A

36. No plano da máxima generalidade, o movimento cognitivo parte do singular abstrato e, através da mediação da esfera da particularidade, geradora de determinações, alcança a singularidade e a universalidade concretas. 
categoria do estranhamento, segundo Lukács, daria conta desta constelação problemática.

Em suma: trabalho enquanto categoria fundante do ser social; objetivação e alienação enquanto momentos de afirmação prática do devenir humano dos homens e estranhamento enquanto momento de negatividade consubstanciado pela gênese de obstáculos sociogenéricos para a explicitação plena da generidade, tais são algumas das conexões fundamentais entre estas categorias no interior da ontologia lukácsiana.

LESSA, S. Lukács: labour, objectivation, alienation. Trans/Form/Ação, São Paulo, v. 15, p. 39-51, 1992.

- ABSTRACT: This article aims to clanify the fundamental distinction between the ontological positivity of objectivation and alienation according to György Lukács and the intrinsic negativity of these concepts among an enormous series of writers. To do so, the article focuses, on this particular, between the Hungarian philosopher and Hegel, who set the classical prototype of the negative concepts of alienation objectivation.

- KEYWORDS: Labour; alienation; objectivation; Lukács; Hegel. 